\title{
Dynamic Interactions of Language with Other Cognitive Processes
}

The ability to understand and produce language is unique to humans, but at the same time, language processing is influenced by additional cognitive processes that other species share. Language may be described as a set of linguistic representations and rules, but it is other cognitive abilities, such as attention and short-term memory, that enable us to access and use those representations in verbal communication. In this role, these "other" cognitive processes are termed "language control" processes. Further, a substantial amount of research links language impairments to impairments of these "control" processes. This view of language abilities and language impairments has important implications for the rehabilitation of language disorders. It assumes that language impairment in aphasia reflects impaired access to linguistic representations rather than loss of language knowledge. Such a perspective allows consideration of treatment hypotheses that emphasize both language content (e.g., semantic or phonological variables) and access to that content (e.g., using priming techniques or focusing on short-term memory for language). Furthermore, this view is in keeping with recent research on factors that will maximize effectiveness of treatment, including style of training (e.g., errorless versus errorful learning ${ }^{1}$ ) and intensity and duration of treatment. ${ }^{2}$

The articles in this issue of Seminars in Speech and Language focus on the role of nonlinguistic cognitive processes in language processing with discussions of the implications of these control processes for our understanding of language impairment and its remediation. The articles were first presented at the Second Annual Eleanor M. Saffran Cognitive Neuroscience Conference at Temple University in Philadelphia, Pennsylvania, in September 2007. This conference was established in honor of Eleanor M. Saffran, a pioneer in neuropsychology and aphasia research. The annual meeting serves as a forum for the interdisciplinary discussion of topics in cognitive neuroscience. It is open to clinical practitioners, scientists, faculty, and students representing the many disciplines that connect in some way with questions concerning cognitive and neural processing.

The first article, by William Hula and Malcolm McNeil, discusses approaches to the study of attention in aphasia and provides evidence for impaired attentional processes in aphasia. The second, by Bruce Crosson, reports a therapy approach that uses intentional processes that enable initiation of action to shift lateralization of word production to the right hemisphere and facilitate word retrieval. The third, by Randi Martin and Corinne Allen, describes executive processes (especially inhibition) and how these are involved in language processing and aphasia. Prahlad Gupta's article provides a tutorial on a relatively new area of investigation, the role of computational models in studying language behaviors and aphasia. He emphasizes that computational models can extend behavioral investigations of language and other cognitive processes but cannot replace them. The next article, by Anjan Chatterjee, reviews the neural underpinnings of "spatial

\footnotetext{
${ }^{1}$ Associate Professor of Communication Sciences and Disorders, Temple University, Philadelphia, Pennsylvania. Dynamic Interactions of Language with Other Cognitive Processes; Guest Editor, Nadine Martin, Ph.D.

Semin Speech Lang 2008;29:167-168. Copyright (C) 2008 by Thieme Medical Publishers, Inc., 333 Seventh Avenue, New York, NY 10001, USA. Tel: +1(212) 584-4662. DOI 10.1055/s-0028-1082881. ISSN 0734-0478.
} 
semantics," the interface of spatial thought and language, and discusses the importance of considering both spatial and object semantics when evaluating language impairment. The final article, by Gerry Stefanatos, discusses the role of temporal processing in impairments of speech perception and factors to consider in the diagnosis of word deafness and Wernicke's aphasia.

Together, these six articles provide a comprehensive introduction to the study of the interaction of language with other cognitive processes. They should provide the reader with a sampling of the many interesting phenomena involved in language processing and the relevance of these phenomena to our understanding and treatment of language disorders.

$$
\begin{array}{r}
\text { Nadine Martin, Ph.D. }{ }^{1} \\
\text { Guest Editor }
\end{array}
$$

\section{REFERENCES}

1. Fillingham JK, Sage K, Lambon Ralph MA. Treatment of anomia using errorless versus errorful learning: are frontal executive skills and feedback important? Int J Lang Commun Disord 2005;4(5): 505-523

2. Raymer AM, Beeson P, Holland A, et al. Translational research in aphasia: from neuroscience to neurorehabilitation. J Speech Lang Hear Res 2008;51(1):S259-S275 